\title{
Chagas cardiomyopathy: The potential effect of benznidazole treatment on diastolic dysfunction and cardiac damage in dogs chronically infected with Trypanosoma cruzi
}

\author{
Fabiane M. Santos ${ }^{\mathrm{a}, \mathrm{b}}$, Ana L. Mazzeti ${ }^{\mathrm{a}}$, Sérgio Caldas ${ }^{\mathrm{d}}$, Karolina R. Gonçalves ${ }^{\mathrm{a}}$, \\ Wanderson G. Lima ${ }^{c}$, Rosália M. Torres ${ }^{e}$, Maria Terezinha Bahia ${ }^{a, c, *}$ \\ a Laboratório de Doenças Parasitárias, Escola de Medicina, Universidade Federal de Ouro Preto, Morro do Cruzeiro, CEP 35400-000, Ouro Preto, Minas \\ Gerais, Brazil

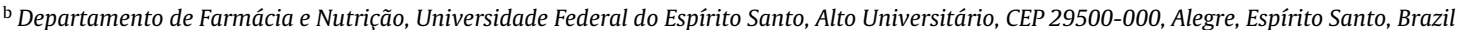 \\ c Departamento de Ciências Biológicas, Instituto de Ciências Exatas e Biológicas, Universidade Federal de Ouro Preto, Morro do Cruzeiro, CEP 35400-000, \\ Ouro Preto, Minas Gerais, Brazil

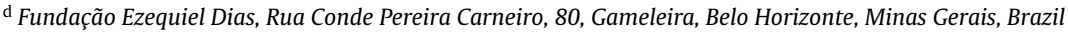 \\ e Faculdade de Medicina, Universidade Federal de Minas Gerais, Avenida Alfredo Balena, 190, Santa Efigênia, CEP 30130-100, Belo Horizonte, Minas Gerais, \\ Brazil
}

\section{A R T I C L E I N F O}

\section{Article history:}

Received 25 November 2015

Received in revised form 24 April 2016

Accepted 15 May 2016

Available online 20 May 2016

\section{Keywords:}

Trypanosoma cruzi

Benznidazole

Kinetoplast DNA follow-up

Diastolic dysfunction

\begin{abstract}
A B S T R A C T
Cardiac involvement represents the main cause of mortality among patients with Chagas disease, and the relevance of trypanocidal treatment to improving diastolic dysfunction is still doubtful. In the present study, we used a canine model infected with the benznidazole-sensitive Berenice-78 Trypanosoma cruzi strain to verify the efficacy of an etiologic treatment in reducing the parasite load and ameliorating cardiac muscle tissue damage and left ventricular diastolic dysfunction in the chronic phase of the infection. The effect of the treatment on reducing the parasite load was monitored by blood PCR and blood culture assays, and the effect of the treatment on the outcome of heart tissue damage and on diastolic function was evaluated by histopathology and echo Doppler cardiogram. The benefit of the benznidazole-treatment in reducing the parasite burden was demonstrated by a marked decrease in positive blood culture and PCR assay results until 30 days post-treatment. At this time, the PCR and blood culture assays yielded negative results for $82 \%$ of the treated animals, compared with only $36 \%$ of the untreated dogs. However, a progressive increase in the parasite load could be detected in the peripheral blood for one year posttreatment, as evidenced by a progressive increase in positive results for both the PCR and the blood culture assays at follow-up. The parasite load reduction induced by treatment was compatible with the lower degree of tissue damage among animals euthanized in the first month after treatment and with the increased cardiac damage after this period, reaching levels similar to those in untreated animals at the one-year follow-up. The two infected groups also presented similar, significantly smaller values for early tissue septal velocity (E' SIV) than the non-infected dogs did at this later time. Moreover, in the treated animals, an increase in the E/E' septal tissue filling pressure ratio was observed when compared with basal values as well as with values in non-infected dogs. These findings strongly suggest that the temporary reduction in the parasite load that was induced by benznidazole treatment was not able to prevent myocardial lesions and diastolic dysfunction for long after treatment.
\end{abstract}

(c) 2016 Elsevier B.V. All rights reserved.

\section{Introduction}

Chagas disease is a vector-borne parasitic infection caused by the kinetoplastid protozoan Trypanosoma cruzi and is an important

* Corresponding author at: Laboratório de Doenças Parasitárias, sala 203, Escola de Medicina, Universidade Federal de Ouro Preto, Ouro Preto, MG, 35400-000, Brazil.

E-mail addresses: mtbahia@nupeb.ufop.br, fabiane.santos@ufes.br (M.T. Bahia). cause of end-stage cardiomyopathy and loss of disability-adjusted life years (DALYs) among young, economically active adults in endemic countries (Coura, 2007; Martins-Melo et al., 2012). An estimated 14,000 people die from Chagas disease each year, mainly due to a chronic cardiac condition that may be associated with other chronic diseases, further increasing mortality (Schmunis and Yadon, 2010; Guariento et al., 2011).

The role of parasite persistence in the pathogenesis of Chagas heart disease has been demonstrated by the presence of $T$. 
cruzi in the heart, along with a low-grade but relentless inflammatory process and myocardial autoimmune injury (Gutierrez et al., 2009; Marin-Neto et al., 2009; Caldas et al., 2013). However, the immunopathological mechanisms involved in the pathogenesis of chagasic cardiomyopathy and the effect of trypanocidal therapy on the clinical course of patients with chronic Chagas heart disease have not been completely elucidated.

The myocardial abnormalities observed in the chronic phase of the $T$. cruzi infection are extremely variable, ranging from mild forms, such as digitiform apical aneurysms and abnormalities of the left ventricular diastolic function only, to significant cardiac chamber dilatation coupled with severe systolic dysfunction (Ianni et al., 2001; Migliore et al., 2004). Echocardiography is a well-established test in clinical practice that provides parameters by which chagasic patients can be analyzed and stratified (Rassi et al., 2014). Early diagnosis of diastolic dysfunction is a good tool for the management of patients with Chagas cardiomyopathy and can improve prognosis (Cianciulli et al., 2006; Garcia-Alvarez et al., 2010).

A number of clinical trials have demonstrated the beneficial effect of etiologic treatment with benznidazole in the acute and recent chronic phases of Chagas disease (Andrade et al., 1996; Andrade et al., 2004; Sosa Estani et al., 1998). However, no definitive consensus has been reached concerning whether benznidazole treatment significantly reduces the parasite burden or symptoms in the established chronic phase of the disease (Marin-Neto et al., 2009). The recently published results of the BENEFIT clinical trial showed that benznidazole treatment of patients with established Chagas cardiomyopathy was able to reduce (although only transiently) blood parasite levels but did not significantly reduce cardiac clinical deterioration through 5 years of follow-up (Morillo et al., 2015). Pre-clinical studies have demonstrated the beneficial effect of etiologic treatment on reducing tissue damage (Garcia et al., 2005; Bahia et al., 2012; Caldas et al., 2014) and on electrocardiographic alterations (Caldas et al., 2013). Others have demonstrated that benznidazole treatment was able to induce a mild improvement in systolic dysfunction in dogs chronically infected with T. cruzi (Santos et al., 2012). However, the authors showed that this improvement in systolic heart function in benznidazole-treated dogs was not accompanied by prevention of growth of the cardiac chambers, including the left atrial volume, a parameter that may also be evaluated to assess left ventricular diastolic cardiac function. Considering these antecedents, the present investigation was undertaken to better elucidate whether trypanocidal therapy with benznidazole in the chronic phase of Chagas disease would be effective in preventing or reducing the left ventricular diastolic dysfunction and tissue damage as well as in reducing the parasite burden immediately and for one year post-treatment.

\section{Methods}

\subsection{Parasite}

The Berenice-78 T. cruzi strain (T. cruzi II), isolated by xenodiagnosis in 1978 (Lana and Chiari, 1986) from the first reported human case of Chagas disease, was used in this study

\subsection{Experimental animals}

Thirty 4-month-old mongrel dogs from the Kennel of the Ouro Preto Federal University (UFOP), Minas Gerais State, Brazil, were used in this study. The animals were fed with commercial chow and water ad libitum. Before the study, the animals were dewormed and vaccinated against several infectious diseases. All procedures and experimental protocols were conducted in accordance with the guidelines of the COBEA (Brazilian College of Animal Experimentation) and with the approval of the Ethics Committee for Animal Experimentation of UFOP (Protocol number 2008/08). The infected animals were inoculated intraperitoneally with 4000 blood trypomastigotes per $\mathrm{kg}$ of body weight and then were divided into two experimental groups: (i) 11 dogs that were treated with benznidazole at $7.0 \mathrm{mg} / \mathrm{kg}$ bid (Q12) for 60 days and (ii) 11 dogs that were maintained as untreated controls. An additional 8 animals were maintained as a non-infected/healthy control group.

\subsection{Drug and treatment scheme}

The drug benznidazole (Bz; N-benzyl-2-nitro-1imidazolacetamide) was synthesized at LAFEPE, Pernambuco, Brazil. The treatment scheme was previously described by Guedes et al. (2002). In all chronic-stage therapeutic schemes, oral treatment was initiated 120 days post-infection.

\subsection{Assessment of parasite clearance}

The parasite load was monitored by blood PCR and blood culture assays performed before treatment and in the 1st, 6th and 12th months post-treatment. Additionally, quantitative real-time PCR (qPCR) was performed on heart tissue samples from the animals euthanized in the 1 st and 12 th months post-treatment.

\subsubsection{Blood $P C R$}

For the PCR assays of the blood, $10 \mathrm{~mL}$ of blood was collected from each animal during follow-up evaluations in the 4th month of infection (before treatment) and at the 1st, 6th and 12 th months post-treatment. The blood samples were mixed with an equal volume of a $6 \mathrm{M}$ guanidine hydrochloride-0.2 $\mathrm{M}$ EDTA solution and were stored for two weeks at room temperature, followed by boiling for $15 \mathrm{~min}$ before DNA was extracted from $200 \mu \mathrm{L}$ aliquots taken from each sample (Guedes et al., 2002). PCR amplification was performed in a total volume of $20 \mu \mathrm{L}$ containing $0.1 \%$ Triton X-100; $10 \mathrm{mM}$ Tris- $\mathrm{HCl}$ (pH 9.0); $75 \mathrm{mM} \mathrm{KCl;} 5 \mathrm{mM}$ $\mathrm{MgCl}_{2} ; 0.2 \mathrm{mM}$ (each) dATP, dTTP, dGTP and dCTP (Sigma Chemical Co.); $1 \mu \mathrm{L}$ of Taq DNA polymerase (Invitrogen, USA); $20 \mathrm{pmol}$ of S35 (5'-AAATAATGTACGGG(T/A)GAGATGCATGA-3') and S36 (5'GGGTTCGATTGGGGTTGGTGT- $3^{\prime}$ ) primers; and $2 \mu \mathrm{L}$ of DNA for each sample (Ávila et al., 1991). The reaction mixture was subjected to 35 cycles of amplification in an automatic thermocycler (Biocycler). The temperature profile was as follows: denaturation at $95^{\circ} \mathrm{C}$ for $1 \mathrm{~min}$ (with a longer initial time of $5 \mathrm{~min}$ at $95^{\circ} \mathrm{C}$ ), $65^{\circ} \mathrm{C}$ for $1 \mathrm{~min}$ for primer annealing and $72^{\circ} \mathrm{C}$ for $1 \mathrm{~min}$ for extension, with a final incubation at $72^{\circ} \mathrm{C}$ for $10 \mathrm{~min}$ to extend the annealed primers. The PCR products were visualized by $6 \%$ polyacrylamide gel electrophoresis, followed by silver staining. All DNA extraction steps and reaction mixtures used for PCR were monitored and compared with positive and negative controls. The PCR analysis was considered negative after three failed DNA extractions for a given sample.

\subsubsection{Blood culture}

Parasite detection was performed by culturing $10 \mathrm{~mL}$ blood samples collected in parallel with the blood used for the DNA extraction and PCR amplification. Blood culture assays were performed for treated and control/untreated dogs, as described by Guedes et al. (2002). The cultures were maintained at $28^{\circ} \mathrm{C}$, homogenized weekly, and examined monthly for up to 120 days for parasite detection.

\subsubsection{Quantitative real-time PCR}

DNA extraction from the left atrium was performed at 1 and 12 months after treatment using a Wizard ${ }^{\circledR}$ Genomic DNA Purification 
Kit (Promega) with certain modifications (Caldas et al., 2012). Using the pGEM-T Easy Vector System (Promega, Madison, WI, USA), a plasmid was constructed by cloning the $182 \mathrm{bp}$ amplicon of $T$. cruzi satellite DNA. The amplicon was generated using the primers TCZF 5'-GCTCTTGCCCACAMGGGTGC-3', where $\mathrm{M}=\mathrm{A}$ or $\mathrm{C}$, and TCZ-R 5'-CCAAGCAGCGGATAGTTCAGG-3', as described by Cummings and Tarleton (2003). The recombinant plasmid was linearized by digestion with NdeI, and the target sequence was purified and quantified using a Qubit ${ }^{\circledR} 2.0$ Fluorometer (Life Technologies). The DNA copy number was calculated, and $100 \mu \mathrm{L}$ of $1 \times 10^{12}$ cloned copies of $T$. cruzi DNA was mixed with $100 \mu \mathrm{L}$ of DNA (5-fold concentrated) from a non-infected dog. The canine housekeeping $\beta$-actin gene was used as the endogenous control for qPCR normalization. Standard curves were generated from five serial dilutions of the mixed DNA in water $(1: 10)$, ranging from $5 \times 10^{9}$ to $5 \times 10^{5}$ copies/ $\mu \mathrm{L}$ for T. cruzi and $1 \times 10^{7}$ to $1 \times 10^{3}$ arbitrary units/ $\mu \mathrm{L}$ for $\beta$-actin.

Assays of qPCR were performed using SYBR Green Master Mix (Applied Biosystems) according to the manufacturer's instructions and the specific primers TCZsat-F 5'-YCTCTGACTCCCACCATTCA3', where $\mathrm{Y}=\mathrm{C}+\mathrm{T}$, and TCZsat-R 5'-GCACTCGGCTGATCGTTT-3' (Invitrogen ${ }^{\mathrm{TM}}$ ), designed by us for $T$. cruzi DNA ( $89 \mathrm{bp}$ ) amplification. The canine $\beta$-actin endogenous control ( $54 \mathrm{bp}$ ) was amplified using the sense primer $5^{\prime}$-CCACTTTCCTGTCTTACCCAA-3' and the antisense primer 5'-AATTAACCACCCACGGTGTT-3' (Guedes et al., 2010) (Invitrogen ${ }^{\mathrm{TM}}$ ). DNA samples were 10 -fold diluted in water before use. Cycles of amplification were carried out in a 7500 Fast Real-Time PCR System (Applied Biosystems). The cycles consisted of an initial denaturation for $10 \mathrm{~min}$ at $95^{\circ} \mathrm{C}$, followed by 40 cycles of $95^{\circ} \mathrm{C}$ for $15 \mathrm{~s}$ and $62^{\circ} \mathrm{C}$ for $1 \mathrm{~min}$, with fluorescence acquisition. Amplification was immediately followed by a melting curve program with an initial denaturation at $95^{\circ} \mathrm{C}$ for $15 \mathrm{~s}$, cooling to $60^{\circ} \mathrm{C}$ for $1 \mathrm{~min}$ and then a stepwise temperature increase of $0.3^{\circ} \mathrm{C} / \mathrm{s}$ from 60 to $95^{\circ} \mathrm{C}$. Each 96 -well reaction plate contained a standard for the curves and two negative controls, consisting of reactions with T. cruzi and $\beta$-actin-specific primers without DNA and reactions with DNA from a non-infected dog. Each DNA sample was quantified in duplicate for the $T$. cruzi and $\beta$-actin targets. The mean values for T. cruzi DNA were normalized by the data obtained for $\beta$-actin, as follows: normalized value $=($ mean $T$. cruzi DNA $/$ mean $\beta$-actin DNA) $\times 4 \times 10^{6}$ (expected mean value for $\beta$-actin).

\subsection{Histopathology and morphometric analysis}

A fragment of approximately $1.0 \mathrm{~cm} \times 1.0 \mathrm{~cm} \times 0.2 \mathrm{~cm}$ from the middle of the right atrial wall was collected for histopathological analysis at 1 and 12 months post-treatment after euthanasia of the dogs. The tissue fragments were fixed in a $10 \%$ buffered formalin solution, dehydrated, cleared and embedded in paraffin. The blocks were cut into $4 \mu \mathrm{m}$-thick sections and stained with hematoxylin and eosin (H\&E) for assessment of the inflammation or with Masson's trichrome for quantitative evaluation of fibrosis. Twenty fields from each H\&E or Masson's trichrome-stained section were randomly chosen at a $40 \times$ magnification, giving a total area of $1.49 \times 10^{6} \mu \mathrm{m}^{2}$ of analyzed myocardium. Images were obtained using a Leica DM 5000 microcamera and the Leica Applications Suite software built into the Leica Q-Win plus VS image analyzer. The inflammatory process was evaluated based on the number of cell nuclei quantified in the myocardial muscle from non-infected and infected animals. The area of fibrosis was quantified using the image segmentation function. All pixels with blue hues in Masson's trichrome-stained sections were selected to build a binary image, and the total area occupied by connective tissue in noninfected and $T$. cruzi-infected dogs was subsequently calculated. The infected animals were considered to have a relevant inflammatory process or an area of fibrosis when the cell nucleus number or the fibrosis area indicated by blue pixels was greater than the

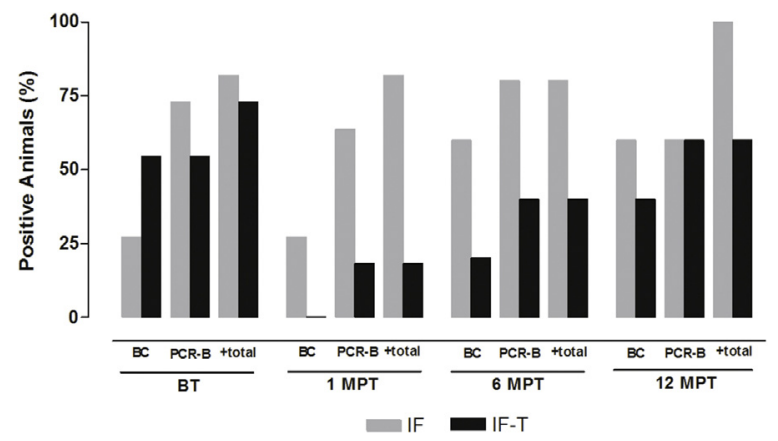

Fig. 1. Influence of benznidazole treatment on the parasite load. Percentage of positive blood culture and blood PCR assays obtained before treatment as well as at 1, 6 and 12 months post-treatment with $7 \mathrm{mg} / \mathrm{kg}$ benznidazole twice daily for 60 days in dogs infected with the Berenice-78 Trypanosoma cruzi strain. IF: untreated infected animals. IF-T: benznidazole-treated infected animals.

median value plus one standard deviation (SD) quantified in the non-infected group.

\subsection{Echocardiography}

All animals were submitted to Doppler echocardiographic exams before infection and in the 1 st and 12th months posttreatment (i.e., 6 and 18 months post-infection). The animals were injected intraperitoneally with the anesthetic thiopental sodium $(0.03 \mathrm{~g} / \mathrm{mL} 0.8 \%$ saline solution $)$ and placed on an insulated electric surface, where the anesthetized dogs were positioned with their limbs perpendicularly orientated to the body (Santos et al., 2012). The left ventricular diastolic function was measured based on the mitral inflow pattern, pulmonary venous flow and pulsed Doppler tissue imaging. The parameters were monitored using a moving Cypress echocardiographic instrument and are well described in early diastolic dysfunction in Chagas heart disease (Garcia-Alvarez et al., 2010). M-mode, two-dimensional and pulsed Doppler echocardiographic studies were performed on each animal according to the method described by the American Society of Echocardiography (Schiller et al., 1989; Keren et al., 1985).

\subsection{Statistical analysis}

The means of the histological inflammatory process quantification and echocardiographic parameters were analyzed via analysis of variance, followed by Tukey's multiple comparison tests. In all cases, differences were considered as significant when $p<0.05$. The correlations of tissue Doppler diastolic dysfunction parameters with the intensity of the fibrosis and inflammation in the right atrium were verified by the Pearson linear correlation test. Statistical calculations were performed using Graph-Pad Prism software.

\section{Results}

\subsection{Blood parasite clearance}

To evaluate the efficacy of benznidazole in clearing the parasitism, detection of $T$. cruzi in the blood samples was performed by PCR and blood culture before treatment and in the 1st, 6 th and 12th months post-treatment. The dogs were treated for 60 consecutive days in the early chronic phase (4th to 6th months after infection). Before the 4th month of infection, when the treatment began, the summations of the positive results verified by PCR and blood culture were similar and greater than $70 \%$ in the infected groups ( 8 of the 11 treated animals and 9 of the 11 untreated animals) (Fig. 1). The infected animals with a negative blood culture and PCR test in 


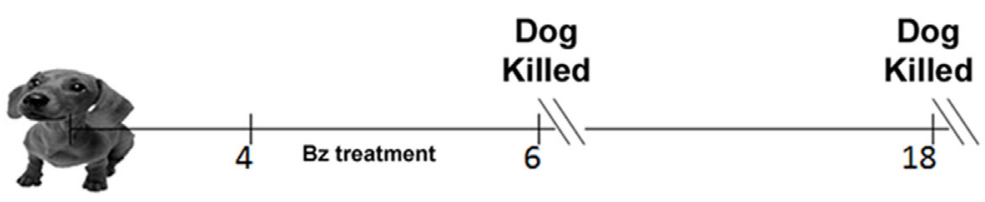

Months of infection

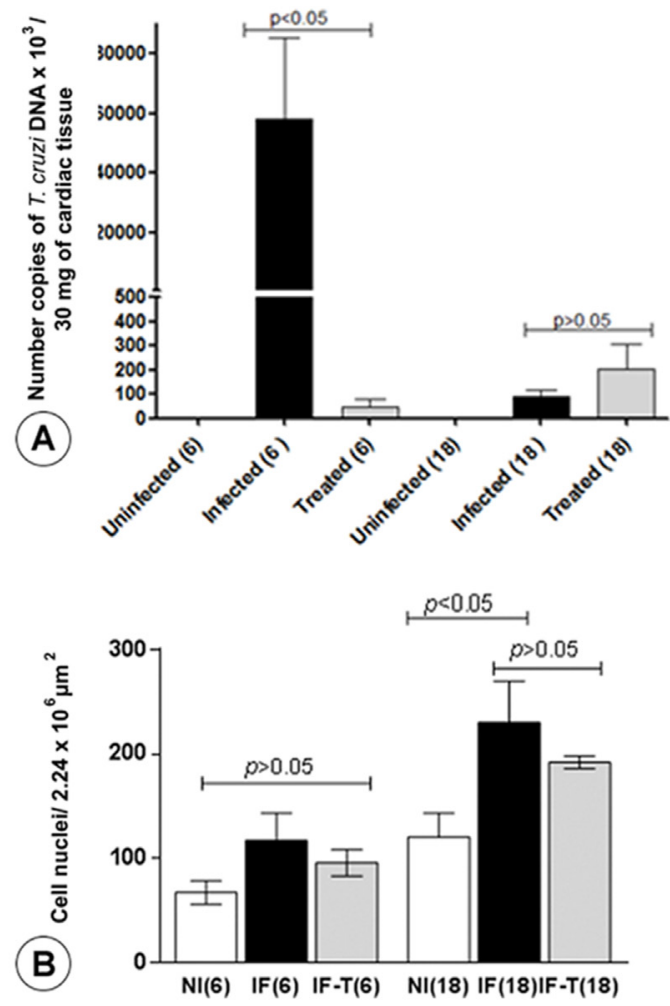

Dogs killed 6 months of infection

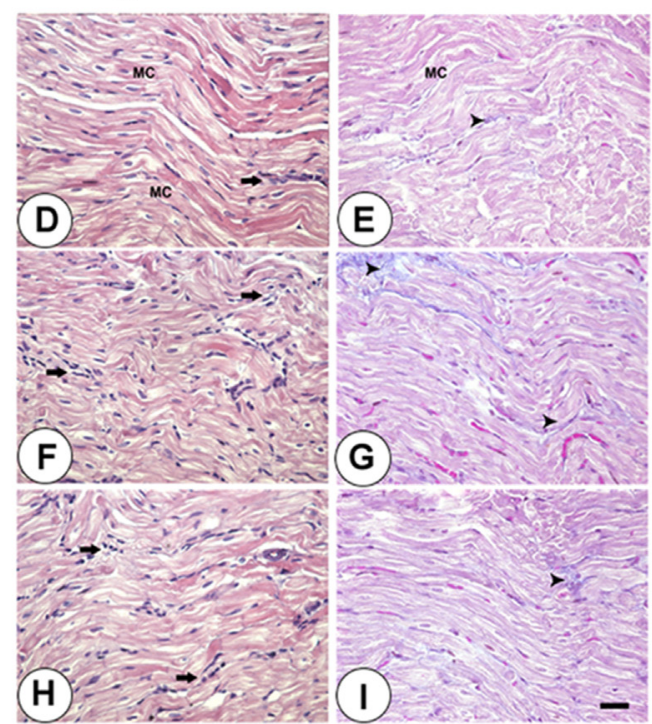

Dogs killed 18 months of infection

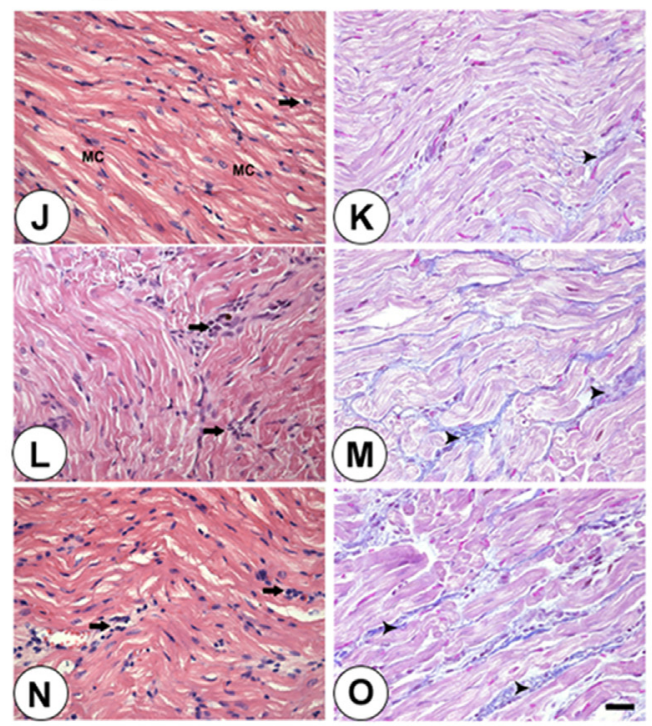

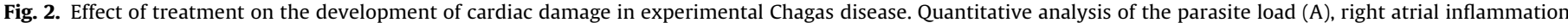

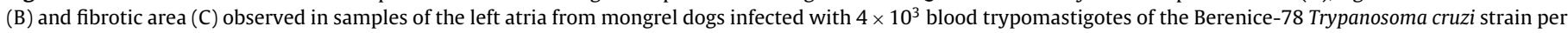

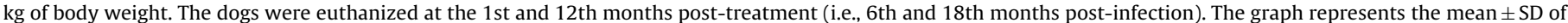

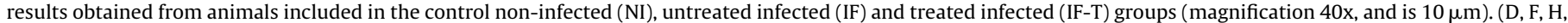

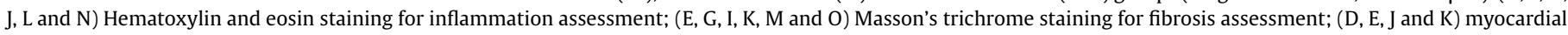
sections from a non-infected dog; (F, G, L and M) sections from an untreated infected dog; $(\mathrm{H}, \mathrm{I}, \mathrm{N}, \mathrm{O})$ sections from a treated infected dog.

this evaluation had been confirmed as having $T$. cruzi infection at the acute stage of the disease by a peripheral blood exam.

Immediately after the trypanocidal chemotherapy, 82\% (9 of 11 ) of the animals originally infected with $T$. cruzi had negative results in the blood PCR assay. The negative results were verified in all blood culture tests, confirming the immediate reduction of the parasite load induced by benznidazole treatment. In contrast, at this time, the parasite or its kinetoplast DNA (kDNA) could be detected in $82 \%$ ( 9 of 11 ) of the animals that were infected and untreated (Fig. 1). Interestingly, the parasite was more easily detected in 

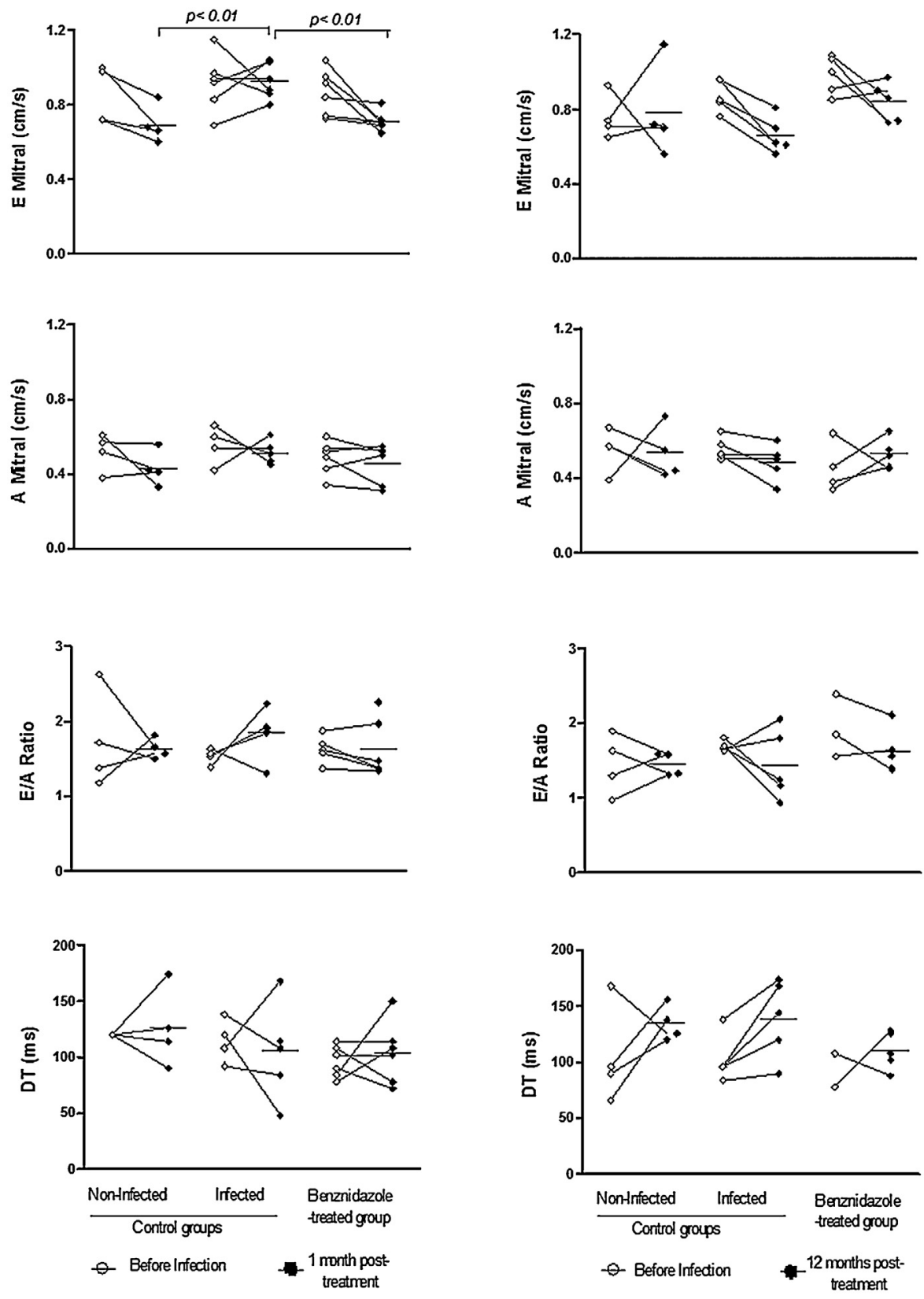

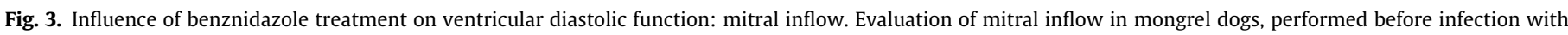

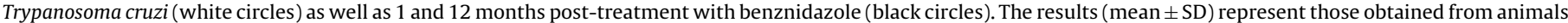
from the control non-infected, untreated infected and benznidazole-treated infected groups. *Statistical significance ( $p<0.05$, as assessed using Tukey's test).

cardiac tissue than in peripheral blood, but at significantly lower levels in the tissue samples obtained from the treated animals relative to the levels observed in the untreated infected animals. Considering the results of the real-time PCR, the mean parasitism detected 30 days after treatment was $45.83 \times 10^{3}$ copies of $T$. cruzi DNA/30 mg of cardiac tissue in treated dogs and $58,032.51 \times 10^{3}$ copies of $T$. cruzi DNA in those without treatment (Fig. 2A).

The follow-up evaluation at one year post-treatment revealed an increase in blood parasitism because the parasite or its kDNA could be detected in 40\% ( 2 of 5 ) of the blood samples collected in the 6th month after treatment and in 60\% (3 of 5) of those collected in the 12 th month post-treatment. The same result was detected in $80 \%$ ( 4 of 5) and in $100 \%$ ( 5 of 5 ) of the blood samples collected from the untreated animals in the 6th and 12 th months post-treatment, respectively (Fig. 1). T. cruzi DNA could be detected at the same levels in all samples of cardiac muscle tissue from the animals in both infected groups, namely, treated or not treated. At this time, could be detected $202.52 \times 10^{3}$ copies of $T$. cruzi DNA/30 mg of cardiac tissue in treated dogs and $88.86 \times 10^{3}$ copies of $T$. cruzi DNA in those without treatment (Fig. 2A).

\subsection{Myocardial inflammatory process}

To assess the effectiveness of benznidazole treatment in ameliorating heart muscle tissue damage, a quantitative analysis of inflammation and fibrosis was performed in the 1st and 12th months post-treatment. No statistically significant variation was observed in the right atrial inflammatory process between the infected groups at 1 month post-treatment. However, in the benznidazole-treated animals, approximately $20 \%$ fewer mononuclear inflammatory cells and 64\% less intrafascicular collagen deposition were detected. Additionally, only the untreated infected 
Table 1

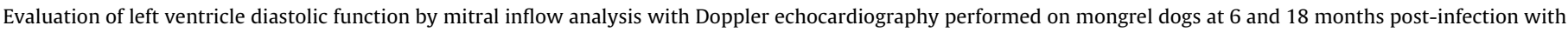
Trypanosoma cruzi, respectively at 1 and 12 months post-treatment with benznidazole, as well as on noninfected animals.

\begin{tabular}{|c|c|c|c|c|c|c|}
\hline \multirow[t]{3}{*}{ Variable } & \multicolumn{6}{|c|}{ Experimental groups } \\
\hline & \multirow[b]{2}{*}{$\mathrm{NI}$} & \multicolumn{2}{|c|}{1 month post-treatment } & \multirow[b]{2}{*}{$\mathrm{NI}$} & \multicolumn{2}{|c|}{12 months post-treatment } \\
\hline & & IF-NT & IF-T & & IF-NT & IF-T \\
\hline $\mathrm{E}(\mathrm{cm} / \mathrm{s})$ & $0.70 \pm 0.1$ & $0.93 \pm 0.1^{\mathrm{a}, \mathrm{c}}$ & $0.71 \pm 0.05^{b}$ & $0.78 \pm 0.25$ & $0.66 \pm 0.1$ & $0.84 \pm 0.1$ \\
\hline $\mathrm{A}(\mathrm{cm} / \mathrm{s})$ & $0.43 \pm 0.1$ & $0.51 \pm 0.06$ & $0.46 \pm 0.11$ & $0.54 \pm 0.14$ & $0.48 \pm 0.10$ & $0.53 \pm 0.08$ \\
\hline E/A ratio & $1.64 \pm 0.14$ & $1.85 \pm 0.30$ & $1.63 \pm 0.39$ & $1.45 \pm 0.15$ & $1.44 \pm 0.47$ & $1.62 \pm 0.30$ \\
\hline DT (ms) & $126.0 \pm 35.33$ & $106.0 \pm 39.56$ & $104.0 \pm 28.06$ & $135.0 \pm 15.87$ & $139.2 \pm 34.83$ & $110.4 \pm 16.82$ \\
\hline
\end{tabular}

NI: noninfected control group; IF-NT: infected nontreated group; IF-T: infected benznidazole-treated group.

a Indicates significant difference relative to the noninfected control group in the corresponding time.

b Indicates significant difference relative to the infected nontreated group.

c Indicates significant difference relative to the infected benznidazole-treated group.

Table 2

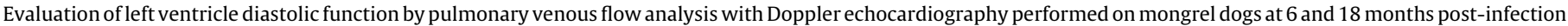
with Trypanosoma cruzi, respectively at 1 and 12 months post-treatment with benznidazole, as well as on noninfected animals.

\begin{tabular}{|c|c|c|c|c|c|c|}
\hline \multirow[t]{3}{*}{ Variable } & \multicolumn{6}{|c|}{ Experimental groups } \\
\hline & \multicolumn{3}{|c|}{1 month post-treatment } & \multicolumn{3}{|c|}{12 months post-treatment } \\
\hline & $\mathrm{NI}$ & IF-NT & IF-T & $\mathrm{NI}$ & IF-NT & IF-T \\
\hline $\mathrm{S}(\mathrm{cm} / \mathrm{s})$ & $0.49 \pm 0.1$ & $0.71 \pm 0.22$ & $0.64 \pm 0.16$ & $0.53 \pm 0.07$ & $0.47 \pm 0.06$ & $0.46 \pm 0.13$ \\
\hline $\mathrm{D}(\mathrm{cm} / \mathrm{s})$ & $0.4 \pm 0.14$ & $0.43 \pm 0.11$ & $0.51 \pm 0.21$ & $0.42 \pm 0.08$ & $0.3 \pm 0.03$ & $0.35 \pm 0.09$ \\
\hline S/D ratio & $1.26 \pm 0.2$ & $1.65 \pm 0.20$ & $1.33 \pm 0.27$ & $1.3 \pm 0.27$ & $1.59 \pm 0.21$ & $1.37 \pm 0.46$ \\
\hline Ar velocity $(\mathrm{cm} / \mathrm{s})$ & $0.26 \pm 0.01$ & $0.29 \pm 0.06$ & $0.31 \pm 0.04$ & $0.31 \pm 0.00$ & $0.29 \pm 0.07$ & $0.31 \pm 0.05$ \\
\hline Ar duration (ms) & $66.0 \pm 0.00$ & $68.0 \pm 3.46$ & $62.67 \pm 15.32$ & $67.5 \pm 9.0$ & $74.0 \pm 8.25$ & $77.6 \pm 6.54$ \\
\hline
\end{tabular}

NI: noninfected control group; IF-NT: infected nontreated group; IF-T: infected benznidazole-treated group.

Table 3

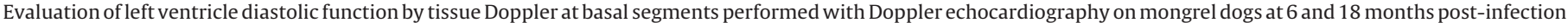
with Trypanosoma cruzi, respectively at 1 and 12 months post-treatment with benznidazole, as well as on noninfected animals.

\begin{tabular}{|c|c|c|c|c|c|c|}
\hline \multirow[t]{3}{*}{ Variable } & \multicolumn{6}{|c|}{ Experimental groups } \\
\hline & \multicolumn{3}{|c|}{1 month post-treatment } & \multicolumn{3}{|c|}{12 months post-treatment } \\
\hline & $\mathrm{NI}$ & IF-NT & IF-T & $\mathrm{NI}$ & IF-NT & IF-T \\
\hline E' SIV $(\mathrm{cm} / \mathrm{s})$ & $0.20 \pm 0.06$ & $0.19 \pm 0.06$ & $0.18 \pm 0.04$ & $0.23 \pm 0.11$ & $0.08 \pm 0.03^{a}$ & $0.09 \pm 0.04^{\mathrm{a}}$ \\
\hline $\mathrm{A}^{\prime} \operatorname{SIV}(\mathrm{cm} / \mathrm{s})$ & $0.10 \pm 0.02$ & $0.13 \pm 0.06$ & $0.10 \pm 0.03$ & $0.16 \pm 0.14$ & $0.07 \pm 0.02$ & $0.10 \pm 0.03$ \\
\hline E'/A' SIV ratio & $2.09 \pm 0.53$ & $1.64 \pm 0.67$ & $2.07 \pm 0.74$ & $1.7 \pm 0.51$ & $1.43 \pm 1.06$ & $0.94 \pm 0.61$ \\
\hline E/E' SIV ratio & $3.85 \pm 1.61$ & $5.73 \pm 3.01$ & $4.24 \pm 1.26$ & $4.15 \pm 1.94$ & $8.76 \pm 2.70$ & $11.26 \pm 4.91^{\mathrm{a}}$ \\
\hline E' LAT $(\mathrm{cm} / \mathrm{s})$ & $0.25 \pm 0.05$ & $0.33 \pm 0.06^{c}$ & $0.22 \pm 0.06^{\mathrm{b}}$ & $0.25 \pm 0.05$ & $0.16 \pm 0.03^{*}$ & $0.18 \pm 0.06$ \\
\hline $\mathrm{A}^{\prime} \mathrm{LAT}(\mathrm{cm} / \mathrm{s})$ & $0.14 \pm 0.03$ & $0.16 \pm 0.03^{c}$ & $0.10 \pm 0.03^{\mathrm{b}}$ & $0.14 \pm 0.05$ & $0.07 \pm 0.01$ & $0.11 \pm 0.04$ \\
\hline E'/A' LAT ratio & $1.90 \pm 0.36$ & $2.08 \pm 0.57$ & $2.31 \pm 0.52$ & $1.95 \pm 0.53$ & $2.33 \pm 0.75$ & $1.71 \pm 0.51$ \\
\hline E/E' LAT ratio & $2.84 \pm 0.76$ & $2.92 \pm 0.56$ & $3.54 \pm 1.0$ & $3.19 \pm 0.73$ & $4.22 \pm 1.12$ & $4.86 \pm 1.03$ \\
\hline
\end{tabular}

NI: noninfected control group; IF-NT: infected nontreated group; IF-T: infected benznidazole-treated group.

a Indicates significant difference in relation to the noninfected control group in the corresponding time.

b Indicates a significant difference relative to the infected nontreated group.

c Indicates a significant difference relative to the infected benznidazole-treated group.

animals had significantly higher fibrosis levels than the noninfected dogs did (Fig. 2B and C). In a later evaluation, at 12 months post-treatment, similar levels of right atrial lesions were detected in treated and untreated infected animals, and the levels in both groups were significantly higher than those present in non-infected dogs (Fig. 2B and C).

\subsection{Left ventricular diastolic dysfunction}

The evaluation of the left ventricular diastolic function was carried out by assessing the mitral inflow and pulmonary venous flow and by tissue Doppler imaging, which were accomplished by performing Doppler echocardiographic exams before the infection and at the 1st and 12th months post-treatment. Before infection, all parameters evaluated were similar among the non-infected, untreated infected and treated infected animals (Figs. 3-5).

The mitral inflow analysis, which involvement measurement of the early diastolic mitral flow velocity (E), late diastolic mitral flow velocity (A), E/A ratio and deceleration time of the E wave (DT), showed that the only differences among the groups occurred at the 1 st month post-treatment, with greater median values of $E$ in the untreated infected animals $(0.93 \mathrm{~cm} / \mathrm{s})$ compared with the treated infected $(0.71 \mathrm{~cm} / \mathrm{s})$ and non-infected $(0.70 \mathrm{~cm} / \mathrm{s})$ animals $(p<0.05)$. There was no variation in the parameters of the mitral inflow analysis among the groups at the 12th month post-treatment, and the values did not vary with respect to the baseline data at either 1 or 12 months post-treatment (Table 1 and Fig. 3).

The evaluation of pulmonary venous flow at the 1 st and 12th months post-treatment revealed similar values among the groups for all of the following parameters: peak $S$ wave inflow pulmonary velocity during ventricular systole $(S)$, peak D wave inflow pulmonary velocity during the early phase of ventricular diastole (D), the corresponding S/D ratio, peak retrograde pulmonary vein velocity or atrial reverse velocity (Ar velocity) and duration of retrograde pulmonary vein or atrial reverse duration (Ar duration) (Table 2). An analysis with respect to the baseline data at the 1st and 12th 

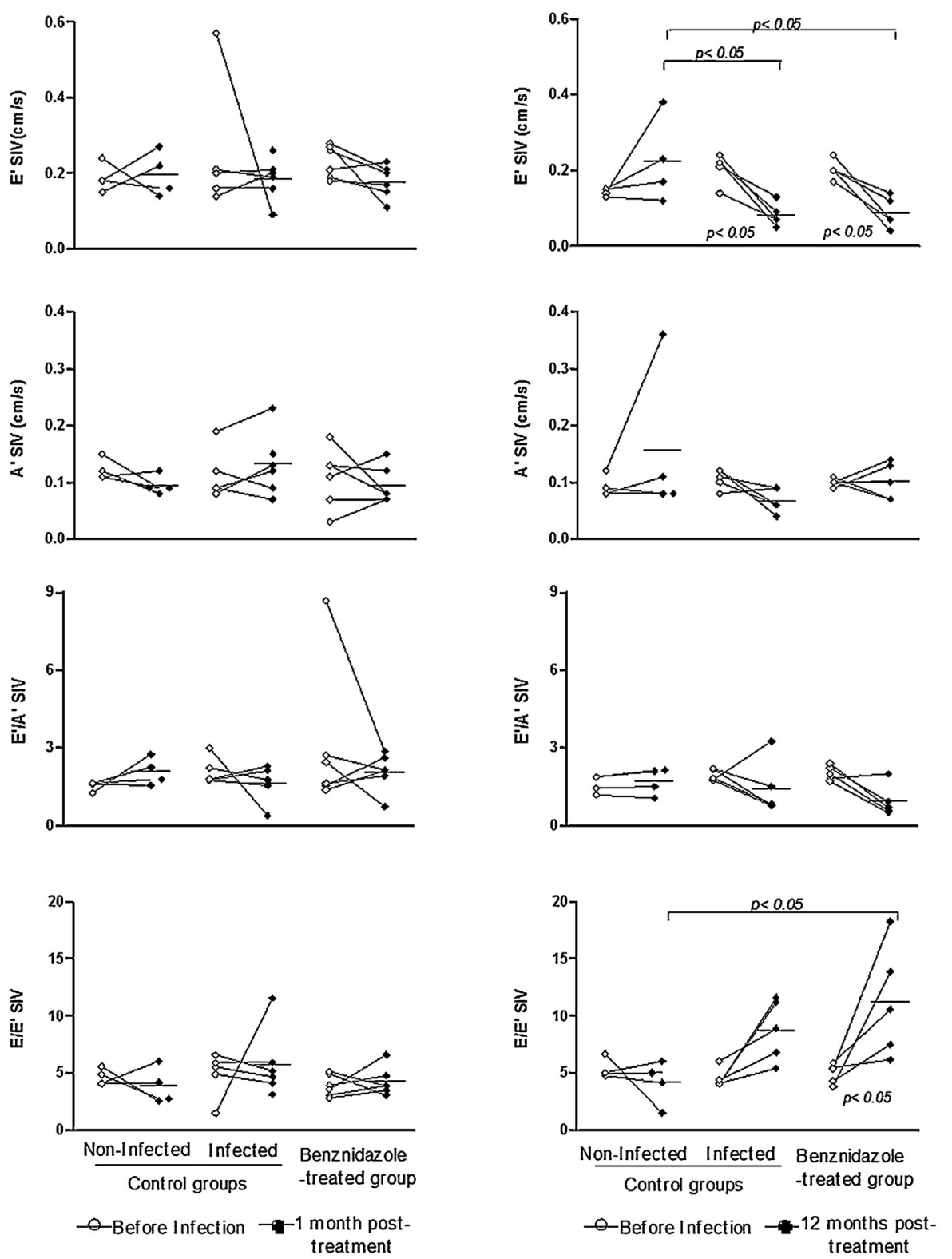

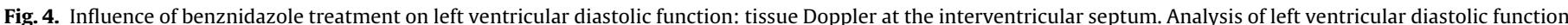

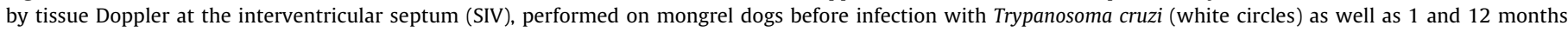

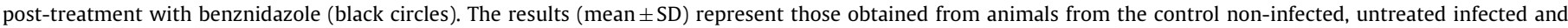
benznidazole-treated infected groups. *Statistical significance ( $p<0.05$, as assessed using Tukey's test).

months post-treatment was not performed due to the absence of differences among the groups.

The study of tissue Doppler at the basal segments showed average values for the peak early (E') and late (A') diastolic myocardial velocities obtained at the septal (SIV) and lateral (LAT) wall positions, the ratios of E'/A' SIV and E'/A' LAT, and the E/E' SIV and LAT ratios to estimate the left ventricular filling pressure. Early and late tissue lateral velocities (E' LAT and A' LAT) at the 1 st month post-infection were similar between non-infected and infected animals, although the treated infected and untreated infected groups showed similar differences as for their baseline data $(p>0.05)$. Afterward, the evaluation at the 12 th month posttreatment revealed a worse reduction in the E' SIV $(p<0.05)$ and E' LAT $(p<0.01)$ in both the treated and the untreated infected animals compared with their baseline data. The non-infected animals showed similar values for these parameters compared with their baseline data and still exhibited a higher E' SIV than either of the infected groups did $(p<0.05)$ and a higher E' LAT than the untreated infected group did $(p<0.05)$. The estimate of the left ventricular filling pressure based on the E/E' septal ratio (E/E' SIV) showed an increase in the treated infected animals compared with their baseline data $(p<0.05)$, higher values than observed in the non-infected dogs $(p<0.05)$, and data that were intermediate relative to the data for the untreated infected group at the 12th month post-treatment (Table 3, Figs. 4 and 5).

To study the influence of the tissue inflammatory process on the development of left ventricular diastolic dysfunction, intrafascicular collagen deposition and the levels of mononuclear inflammatory cells were assessed based on the tissue Doppler parameters using the Pearson linear correlation test. Fibrosis and mononuclear inflammatory cells were correlated with the E' SIV velocity, E'/A' SIV ratio and E/E' SIV ratio $(p<0.01)$. The E/E' LAT ratio was still correlated with the inflammatory cells $(p<0.01)$. The values of the E/E' SIV and E/E' LAT ratios demonstrated direct correlations, whereas 

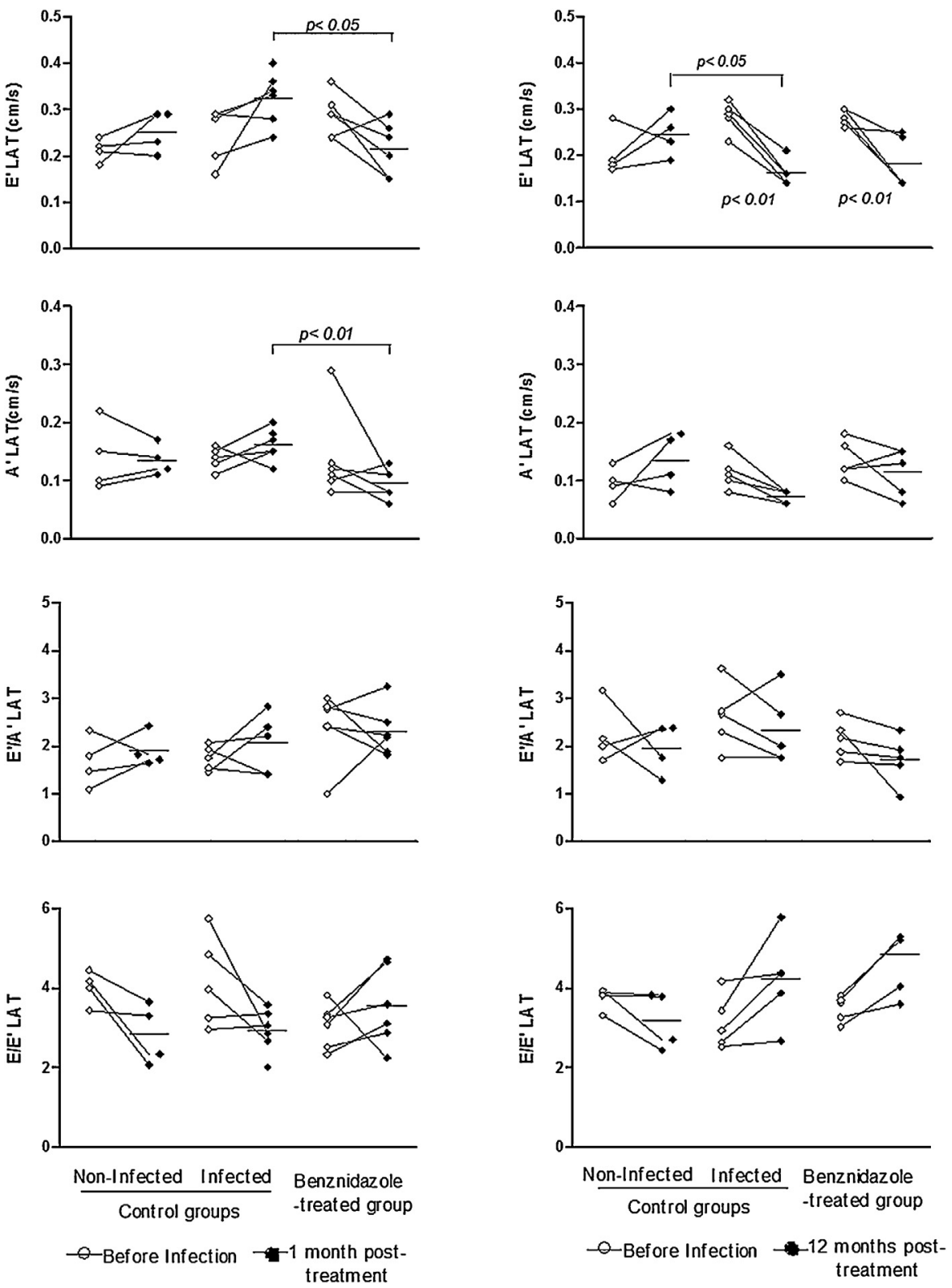

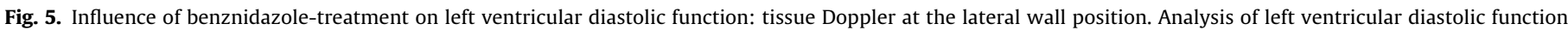

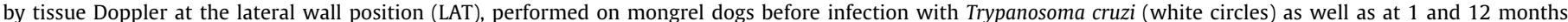

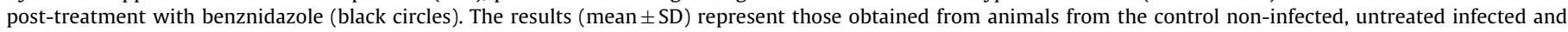
benznidazole-treated infected groups. *Statistical significance $(p<0.05$, as assessed using Tukey's test).

those of the E' SIV and E'/A' SIV were proportionally lower as the levels of tissue inflammation increased (Fig. 6).

\section{Discussion}

Benznidazole treatment has recently been specifically recommended for all patients with Chagas disease, even though the experimental and clinical evidence that is currently available is insufficient to support the routine use of etiologic treatment in chronic patients (Viotti et al., 2006; Marin-Neto et al., 2009).

We used a canine model infected with the benznidazolesensitive Berenice-78 strain to verify the drug's efficacy in reducing the parasite load and ameliorating cardiac muscle tissue damage and left ventricular diastolic dysfunction. Here, the benefit of benznidazole treatment in reducing the parasite burden was demonstrated by the marked decrease in positive results for blood culture and PCR assays until 30 days post-treatment. At that time, the PCR and blood culture assays had negative results for $82 \%$ of the treated animals, compared with only $36 \%$ of the untreated dogs. Nevertheless, a progressive increase in positive results for both the PCR and the blood culture assays was detected throughout the evaluation period. Overall, our results show that the negative blood PCR or blood culture results obtained immediately after the etiologic treatment may be predictive not of a cure, but rather of only a transitory reduction in the parasite burden; this finding suggests that the parasites remain, but at levels below the limits of detection of the methods used. The qPCR data for the tissue samples from benznidazole-treated dogs at one month after treatment and at 12 months post-treatment support this hypothesis by showing the persistence of the parasite in the tissues of treated animals, and even those in which the parasite was not detected in the peripheral blood by PCR or by blood culture. The results of the quantitative estimates of the parasite loads in cardiac tissue 12 

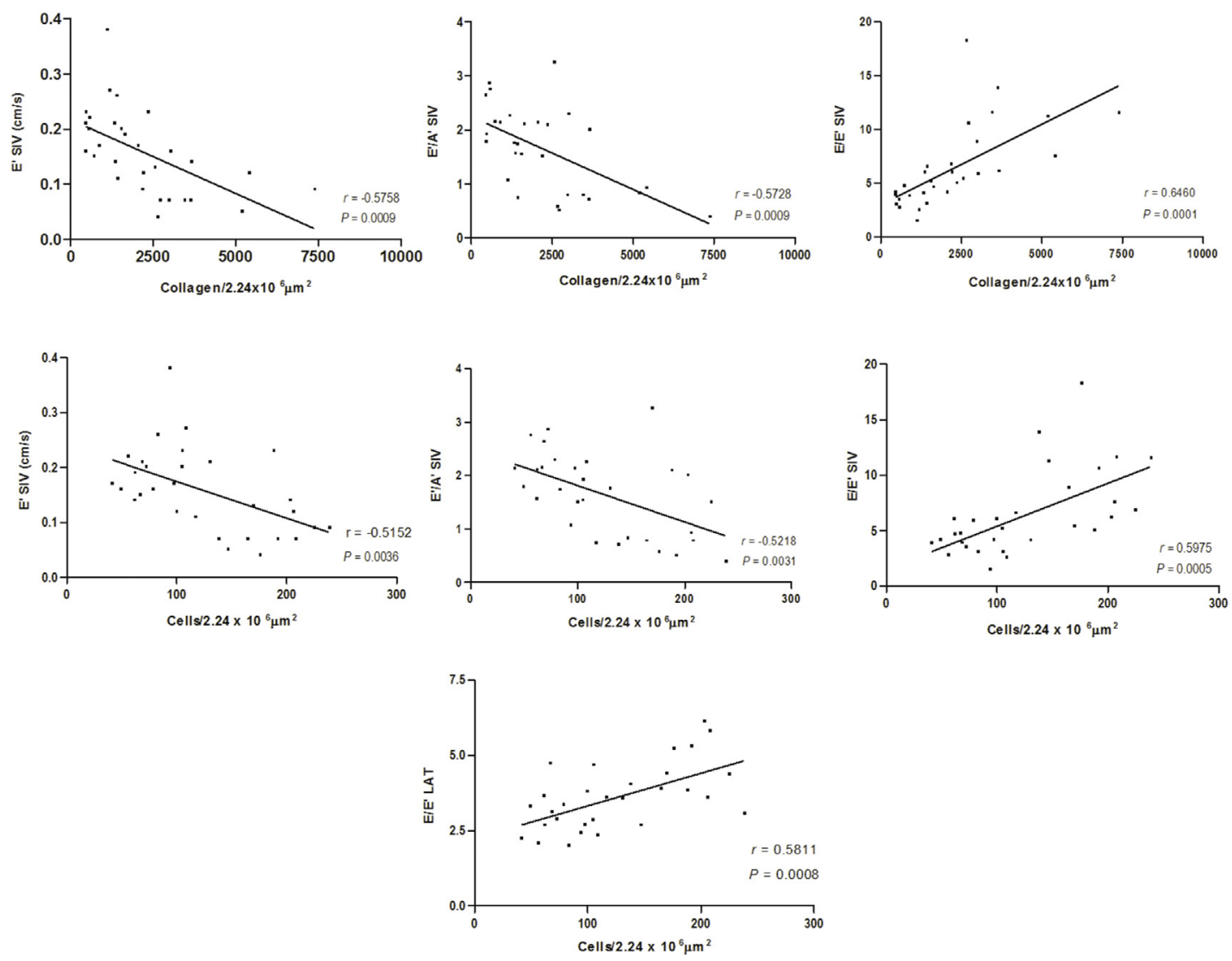

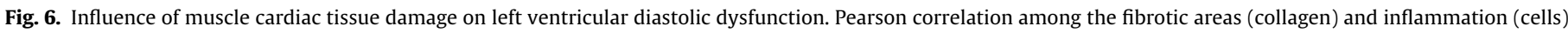
in the right atrium according to E' SIV, E'/A' SIV, and E/E' SIV and between inflammatory cells and E/E' LAT.

months after treatment confirm the persistence of parasitism in the benznidazole-treated dogs.

Our previous studies in dogs infected with the Berenice-78 strain showed that benznidazole treatment in the acute phase (20-30 days after infection) was able to cure $75-100 \%$ of animals, reducing tissue damage and preventing electrocardiographic alterations (Guedes et al., 2002; Caldas et al., 2013). These observations suggest that the treatment failure detected in the present study was not due to the genetic resistance of the Berenice-78 strain to the drug, but rather to a phenotypic characteristic. This hypothesis is in line with the observations of others, showing that in vivo resistance to multiple compounds can vary with the host species and becomes more evident with an increasing length of infection (Dos Santos et al., 2008; Caldas et al., 2008; Bustamante et al., 2013). According to Bustamante et al. (2013), failure in etiologic treatment could also be related to the tissue distribution of parasites and the inaccessibility of certain cells or tissues to the drug.

However, the results of experimental studies should be analyzed with caution, as it is unclear which experimental model is the most appropriate for translation into humans. A number of experimental studies have already demonstrated the effects of the route of infection; the size of the inocula; and the animal's weight, sex, and age on the outcomes of animal infection. According to Chatelain and Konar (2015), a chronic Chagas disease model would ideally offer IgG negativity, negative parasitemia, positive serology, survival, and measures of inflammation markers in the heart and other organs. Along these lines, the dog model shows progression to a chronic phase that closely reflects human disease, so it may be concluded that this is one of the best available in vivo models for Chagas disease (Andrade, 1984; Lana et al., 1992; Bahia et al., 2002; Guedes et al., 2010; Santos et al., 2012; Caldas et al., 2013).
In the present study, the parasite load reduction induced by treatment in the early chronic phase was compatible with the lesser tissue damage among animals euthanized in the first month after treatment. At this time, a higher level of fibrosis was detected in the cardiac muscle tissue among the untreated infected animals $\left(2750.442 \pm 2369.27\right.$ collagen $\left./ 74,931.3 \mu \mathrm{m}^{2}\right)$ relative to the fibrosis detected in the treated dogs $(1017.57 \pm 368.95$ collagen $/ 74,931.3 \mu \mathrm{m}^{2}$ ). However, the large SDs in cardiac damage detected among the untreated infected animals prevented the detection of significant differences between untreated infected and treated infected animals, but only the untreated infected animals had fibrosis levels significantly higher than those in noninfected animals. Consistent with the parasite loads very similar levels of fibrosis could be detected between untreated infected (3369.48 \pm 1098.12 collagen $\left./ 74,931.3 \mu \mathrm{m}^{2}\right)$ and treated infected $\left(3966.65 \pm 995.70\right.$ collagen/74,931.3 $\left.\mu \mathrm{m}^{2}\right)$ animals at 12 months after treatment. These findings allow to formulate the hypothesis that in the absence of cure, the treatment response may be beneficial in the early stages after treatment; however, the later lack of control of the parasite would allow tissue damage to occur. Our findings are in agreement with the results of the recently concluded BENEFIT clinical trial, in which it was found that benznidazole therapy in patients with established Chagas cardiomyopathy significantly (but transiently) reduced serum parasite levels through 5 years of follow-up, although cardiac clinical deterioration was not significantly reduced (Morillo et al., 2015). Based on the results of the BENEFIT study and those of the present work, the high levels (94\%) of blood parasite DNA clearance observed in the Molina et al. (2014) study may simply reflect a transient reduction of the parasite load of the patients, not sustained suppression of the parasite 
load or parasitological cure, and as such do not guarantee a positive clinical outcome in the medium to long term.

To assess whether the transient reduction in the parasite burden by benznidazole treatment would affect the outcome of cardiac diastolic function, the left ventricular diastolic function was verified based on the mitral flow, pulmonary venous flow and tissue Doppler. In the clinical setting, evaluation of diastolic ventricular function is complicated by the coexistence of more than one of the factors that affect diastolic filling, and for this reason, an integrated approach involving various Doppler echocardiographic parameters for evaluation and quantification of the filling pressures is the best way to assess diastolic function. A change in diastolic function may contribute significantly to the production of symptoms in various cardiac diseases, even in the presence of normal systolic function (Dougherty et al., 1984; Sonnenblick, 1988; Aguirre et al., 1990). It has also been shown that diastolic dysfunction can have an early onset, preceding the occurrence of systolic dysfunction (Hirota, 1980; Brutsaert, 1983; Nishimura et al., 1989). According to Cianciulli et al. (2006), a lower E/A ratio and a lengthening of the deceleration time of early diastolic filling (DT) revealed an early disorder of the left ventricular diastolic function in patients with Chagas disease, and these early diastolic disorders can also be detected in a great number of patients with other heart diseases. However, the assessment of diastolic function by mitral Doppler suffers significant limitations, as the curve changes according to age, heart rate and hemodynamic conditions, whereas tissue Doppler is less sensitive to load changes (Nishimura et al., 1990; Ayuela and Vilchez, 2004).

The present study showed that tissue Doppler was the best tool to demonstrate the worsening in the left ventricular diastolic function in the infected animals. The absence of significant differences in the tissue Doppler parameters in the infected groups between their baseline and six months post-infection reveals that the higher E' LAT and A' LAT velocities presented by the untreated infected animals compared with the treated infected dogs at 30 days posttreatment may have occurred due to an elevation of preload (end-diastolic stress), and not to the infection by $T$. cruzi. This concept was also demonstrated, but to a greater degree, by the highest E mitral velocity in these same animals because mitral inflow parameters are more preload dependent than tissue Doppler variables are (Oliveira et al., 2009). These early alterations did not remain at the time of the later evaluation, at 12 months posttreatment, whereas an interesting reduction of the E' SIV and E' LAT velocities occurred in both infected groups, beyond the $\mathrm{E} / \mathrm{E}$ ' ratio elevation that occurred in the treated infected animals. These later findings are in agreement with the definition of diastolic dysfunction, which is the inability to accept blood flow at all or an inability to do so without a compensatory increase in left atrial pressure (Stauffer and Gaasch, 1990). The reduction of E' (SIV and LAT) reflects impaired myocardial relaxation, whereas the growth of the E/E' ratio reflects the elevation of the left ventricular filling pressure (Dokainish, 2007). The lower E' velocity and the lengthening of the E/E' ratio according to the worsening of cardiomyopathy dysfunction were in agreement with the increase in fibrosis and the progression of heart inflammation in the experimental dogs evaluated in this work, as well as with the stratification of heart dysfunction in chagasic patients demonstrated in other work (Nascimento et al., 2013; Garcia-Alvarez et al., 2010).

Interestingly, our previous study (Santos et al., 2012) showed that benznidazole treatment in early chronic Chagas disease slightly ameliorated, but was unable to efficiently prevent, longterm left ventricular systolic cardiac dysfunction. In fact, only untreated infected animals exhibited significantly worse values for classical parameters for assessing systolic dysfunction relative to non-infected dogs. However, both T. cruzi-infected groups (treated or not) experienced a significant decrease in these cardiac systolic function parameters at 18 months post-infection (12 months after treatment) compared with baseline values. In addition, the same previous work still revealed that benznidazole treatment of chronic T. cruzi infection was unable to prevent the long-term development of cardiomegaly, including an increase in the left atrial volume (Santos et al., 2012). In the present study, the absence of significant benefits of benznidazole treatment at a chronic stage of $T$. cruzi infection in terms of ameliorating cardiomyopathy evolution was further clarified, and the results were in agreement with our previous findings for the left atrial volume, a parameter whose increase may be related to left ventricular diastolic dysfunction. Despite the limited number of animals used in each experimental group ( 11 benznidazole-treated infected animals, 11 untreated infected animals and 8 non-infected controls), these findings permit the conclusion that the cardiac structural and functional alterations in the infected animals were associated with the parasite load in the heart.

An overall analysis of our results indicates that the temporary suppressive activity of treatment with benznidazole during the chronic stage of Chagas disease in Berenice-78 T. cruzi straininfected mongrel dogs was not able to affect the outcome of the myocardial pathophysiological degenerative process. The posttreatment parasite rebound in the long term and the development of diastolic dysfunction correlated with heart lesions showed that benznidazole treatment in the early chronic phase was not efficient at preventing the progression of cardiomyopathy disease in dogs infected with the Berenice-78 T. cruzi strain, even though a slight improvement in systolic dysfunction had previously been shown. Based our present findings such therapeutic interventions must aim at a profound and sustained, not short term, suppression of the parasite load of infected patients.

\section{Conflict of interest}

The authors declare that they have no conflict of interest.

\section{Acknowledgments}

This work received financial support from the Fundação de Amparo a Pesquisa do Estado de Minas Gerais (Fapemig); Conselho Nacional de Desenvolvimento Científico e Tecnológico (CNPq); Universidade Federal de Ouro Preto and research fellowships from Conselho Nacional de Desenvolvimento Científico e Tecnológico (M. T. B.).

\section{References}

Ávila, H.A., Sigman, D.S., Cohen, L.M., Millikan, R.C., Simposon, L., 1991. Polymerase chain reaction amplification of Trypanosoma cruzi kinetoplast minicircle DNA isolation from whole blood lysates: diagnosis of chronic Chagas' disease. Mol. Biochem. Parasitol. 40, 211-222.

Aguirre, F.V., Pearson, A.C., Lewen, M.K., McCluskey, M., Labowitz, A.J., 1990. Identifying congestive heart failure patient whose systolic function is normal. Cardiol. Board Rev. 7, 9-33.

Andrade, A.L., Zicker, F., Oliveira, R.M., Almeida, S.S., Luquetti, A., Travassos, L.R., Almeida, I.C., Andrade, S.S., Andrade, J.G., Martelli, C.M., 1996. Randomised trial of efficacy of benznidazole in treatment of early Trypanosoma cruzi infection. Lancet 348 (9039), 1407-1413.

Andrade, A.L., Martelli, C.M., Oliveira, R.M., Silva, S.A., Aires, A.I., Soussumi, L.M., Covas, D.T., Silva, L.S., Andrade, J.G., Travassos, L.R., Almeida, I.C., 2004. Short report: benznidazole efficacy among Trypanosoma cruzi infected adolescents after a six-year follow-up. Am. J. Trop. Med. Hyg. 71 (5), 594-597.

Andrade, Z.A., 1984. The canine model of Chagas' disease. Mem. Inst. Oswaldo Cruz 79, 77-83.

Ayuela, J.M., Vilchez, F.G., 2004. Estimación de las presiones de llenado de ventrículo izquierdo por ecocardiografía Doppler en pacientes críticos. Med. Intensiva 28 (1), 20-25.

Bahia, M.T., Tafuri, W.L., Caliari, M.V., Veloso, V.M., Carneiro, C.M., Coelho, G.L., Lana, M., 2002. Comparison of Trypanosoma cruzi infection in dogs inoculated with blood or metacyclic trypomastigotes of Berenice-62 and Berenice-78 
strains via intraperitoneal and conjunctival routes. Rev. Soc. Bras. Med. Trop. 35 (4), 339-345.

Bahia, M.T., Andrade, I.M., Martins, T.A.F., Nascimento, A.F.S., Diniz, L.F., Caldas, I.S., Talvani, A., Trunz, B.B., Torreele Els Ribeiro, I., 2012. Fexinidazole: a potencial new drug candidate for Chagas disease. PLoS Negl. Trop. Dis. 6 (11), e1870.

Brutsaert, D.L., 1983. Is relaxation really impaired in cardiac failure? Eur. Heart J. 4 (A), 43-48.

Bustamante, J.M., Craft, J.M., Crowe, B.D., Ketchie, S.A., Tarleton, R.L., 2013. New, combined, and reduced dosing treatment protocols cure Trypanosoma cruzi infection in mice. J. Infect. Dis. 209 (1), 150-162.

Caldas, S., Santos, F.M., Lana, M., Diniz, L.F., Machado-Coelho, G.L.L., Veloso, V.M., Bahia, M.T., 2008. Trypanosoma cruzi: acute and long-term Infection in the vertebrate host can modify the response to benznidazole. Exp. Parasitol. 118, 315-323.

Caldas, S., Caldas, I.S., Diniz, L.F., Lima, W.G., Oliveira, R.P., Cecílio, A.B., Ribeiro, I., Talvani, A., Bahia, M.T., 2012. Real-time PCR strategy for parasite quantification in blood and tissue samples of experimental Trypanosoma cruzi infection. Acta Trop. 123 (3), 170-177.

Caldas, I.S., Guedes, P.M.M., Santos, F.M., Diniz, L.F., Martins, T.A.F., Nascimento, A.F.S., Azevedo, M.A., Lima, W.G., Neto, R.M.N., Torres, R.M., Talvani, A., Bahia, M.T., 2013. Myocardial scars correlate with eletrocardiographic changes in chronic Trypanosoma cruzi infection for dogs treated with benznidazole. Trop. Med. Int. Health 18 (1), 75-84.

Caldas, S., Caldas, I.S., Cecílio, A.B., Diniz, L.F., Talvani, A., Ribeiro, I., Bahia, M.T., 2014. Therapeutic responses to different anti-Trypanosoma cruzi drugs in experimental infection by benznidazole-resistant parasite stock. Parasitology 21, $1-10$.

Chatelain, E., Konar, N., 2015. Translational challenges of animal models in Chagas disease drug development: a review. Drug Des. Dev. Ther. 19 (9), 4807-4823.

Cianciulli, T.F., Lax, J.A., Saccheri, M.C., Papantoniou, A., Morita, L.A., Prado, N.G., Dorelle, A.N., Riarte, A.R., Prezioso, H.A., 2006. Early detection of left ventricular diastolic dysfunction in Chagas' disease. Cardiovasc. Ultrasound 4 (18), 1-7.

Coura, J.R., 2007. Chagas disease: what is known and what is needed-a background article. Mem. Inst Oswaldo Cruz 102 (1), 113-122.

Cummings, K.L., Tarleton, R.L., 2003. Rapid quantitation of Trypanosoma cruzi in host tissue by real-time PCR. Mol. Biochem. Parasitol. 129 (1), 53-59.

Dokainish, H., 2007. Combining tissue Doppler echocardiography and B-type natriuretic peptide in the evaluation of left ventricular filling pressures: review of the literature and clinical recommendations. Can. J. Cardiol. 23 (12), 983-989.

Dos Santos, F.M., Caldas, S., de Assis Cáu, S.B., Crepalde, G.P., de Lana, M., Machado-Coelho, G.L., Veloso, V.M., Bahia, M.T., 2008. Trypanosoma cruzi: induction of benznidazole resistance in vivo and its modulation by in vitro culturing and mice infection. Exp. Parasitol. 120, 385-390.

Dougherty, A.H., Naccarelli, G.V., Gray, E.L., Hicks, C.H., Goldstein, R.A., 1984 Congestive heart failure with normal systolic function. Am. J. Cardiol. 54, 778-782.

Garcia, S., Ramos, C.O., Senra, J.F.V., Vilas-Boas, F., Rodrigues, M.M., Campos-de-Carvalho, A.C., Ribeiro-dos-Santos, R., Soares, M.B., 2005. Treatment with Benznidazole during the chronic phase of experimental Chagas' disease decreases cardiac alterations. Antimicrob. Agent Chem. 49 (4), 1521-1528.

Garcia-Alvarez, A., Sitges, M., Pinazo, M.J., Regueiro-Cueva, A., Posada, E., Poyatos, S., Ortiz-Pérez, J.T., Heras, M., Azqueta, M., Gascon, J., Sanz, G., 2010. Chagas cardiomiopathy: the potential of diastolic dysfunction and brain natriuretic peptide in the early identification of cardiac damage. PLoS Negl. Trop. Dis. 4 (9), e826.

Guariento, M.E., Carrijo, C.M., Almeida, E.A., Magna, L.A., 2011. Perfil clínico de idosos portadores de doença de Chagas atendidos em serviço de referência. Rev. Bras. Clin. Med. 9, 20-24.

Guedes, P.M., Veloso, V.M., Tafuri, W.L., Galvão, L.M., Carneiro, C.M., Lana, M., Chiari, E., AtaideSoare, K., Bahia, M.T., 2002. The dog as model for chemotherapy of the Chagas' disease. Acta Trop. 84, 9-17.

Guedes, P.M., Veloso, V.M., Talvani, A., Diniz, L.F., Caldas, I.S., Do-Valle-Matta, M.A., Santiago-Silva, J., Chiari, E., Galvão, L.M., Silva, J.S., Bahia, M.T., 2010. Increased type 1 chemokine expression in experimental Chagas disease correlates with cardiac pathology in beagle dogs. Vet. Immunol. Immunopathol. 138 (1-2), 106-113.

Gutierrez, F.R.S., Guedes, P.M.M., Gazzinelli, R.T., Silva, J.S., 2009. The role of parasite persistence in pathogenesis of Chagas heart disease. Parasite Immunol. 31, 673-685.

Hirota, Y.A., 1980. A clinical study of left ventricular relaxation. Circulation 62 (4), 756-763.
Ianni, B.M., Arteaga, E., Frimm, C.C., Pereira Barretto, A.C., Mady, C., 2001. Chagas heart disease: evolutive evaluation of electrocardiographic and echocardiographic parameters in patients with the indeterminate form. Arq. Bras. Cardiol. 77 (1), 59-62.

Keren, G., Sherez, J., Megidish, R., Levitt, B., Laniado, S., 1985. Pulmonary venous flow pattern- its relationship to cardiac dynamics: a pulsed Doppler echocardiographic study. Circulation 71, 1105-1112.

Lana, M., Chiari, E., 1986. Caracterização biológica comparativa das cepas Berenice e Berenice-78 de Trypanosoma cruzi isoladas da mesma paciente em diferentes períodos. Mem. Inst. Oswaldo Cruz 81, 247-253.

Lana, M., Chiari, E., Tafuri, W.L., 1992. Experimental Chagas' disease in dogs. Mem. Inst. Oswaldo Cruz 87 (1), 59-71.

Marin-Neto, J.A., Rassi Jr, A., Avezum Jr, A., Mattos, A.C., Rassi, A., 2009. The BENEFIT trial: testing the hypothesis that trypanocidal therapy is beneficial for patients with chronic Chagas heart disease. Mem. Inst. Oswaldo Cruz 104 (1), 319-324.

Martins-Melo, F.R., Alencar, C.H., Ramos Jr., A.N., Heukelbach, J., 2012. Epidemiology of mortality related to Chagas' disease in Brazil, 1999-2007. PLoS Negl. Trop. Dis. 6 (2), e1508.

Migliore, R.A., Adaniya, M.E., Tamagusuku, H., Lapuente, A., 2004. Assessment of diastolic function in Chagas disease with pulsed Doppler tissue imaging. Arch. Cardiol. Mex. 74 (1), 31-38.

Molina, I., Gómez i Prat, J., Salvador, F., Treviño, B., Sulleiro, E., Serre, N., Pou, D. Roure, S., Cabezos, J., Valerio, L., Blanco-Grau, A., Sánchez-Montalvá, A., Vidal, X., Pahissa, A., 2014. Randomized trial of posaconazole and benznidazole for chronic Chagas' disease. N. Engl. J. Med. 370 (20), 1899-1908.

Morillo, C.A., Marin-Neto, J.A., Avezum, A., Sosa-Estani, S., Rassi Jr., A., Rosas, F., Villena, E., Quiroz, R., Bonilla, R., Britto, C., Guhl, F., Velazquez, E., Bonilla, L., Meeks, B., Rao-Melacini, P., Pogue, J., Mattos, A., Lazdins, J., Rassi, A., Connolly, S.J., Yusuf, S., 2015. Randomized trial of benznidazole for Chronic Chagas' cardiomyopathy. N. Engl. J. Med. 373 (14), 1295-1306.

Nascimento, C.A., Gomes, V.A., Silva, S.K., Santos, C.R., Chambela, M.C., Madeira, F.S., Holanda, M.T., Brasil, P.E., Sousa, A.S., Xavier, S.S., Hasslocher-Moreno, A.M., Cunha, A.B., Saraiva, R.M., 2013. Left atrial and left ventricular diastolic function in chronic Chagas disease. J. Am. Soc. Echocardiogr. 26, 1424-1433.

Nishimura, R.A., Housmans, P.R., Hatle, L.K., Tajik, A.J., 1989. Assessment of diastolic function of the heart: background and current applications of Doppler echocardiography-part 1: physiologic and a pathophysiologic features. Mayo Clin. Proc. 64, 71-81.

Nishimura, R.A., Abel, M.D., Hatle, L.K., Tajik, A.J., 1990. Relation of pulmonary vein to mitral flow velocities by transesophageal Doppler echocardiography: effect of different loading conditions. Circulation 81, 1488-1497.

Oliveira, B.M.R., Botoni, F.A., Ribeiro, A.L.P., Pinto, A.S., Reis, A.M., Nunes, M.C.P., Rocha, M.O.C., 2009. Correlation between BNP Levels and Doppler echocardiographic parameters of left ventricle filling pressure in patients with chagasic cardiomyophaty. Echocardiography 26 (5), 521-527.

Rassi, D.C., Vieira, M.L.C., Arruda, A.L.M., Hotta, V.T., Furtado, R.G., Rassi, D.T., Rassi, S., 2014. Echocardiographic parameters and survival in Chagas heart disease with severe systolic dysfunction. Arq. Bras. Cardiol. 102 (3), 245-252.

Santos, F.M., Lima, W.G., Gravel, A.S., Martins, T.A.F., Talvani, A., Torres, R.M., Bahia, M.T., 2012. Cardiomyopathy prognosis after benznidazole treatment in chronic canine Chagas' disease. J. Antimicrob. Chemother. 67, 1987-1995.

Schiller, N.B., Shah, P.M., Crawford, M., DeMaria, A., Devereux, R., Feigenbaum, H., Gutgesell, H., Reichek, N., Sahn, D., Schnittger, I., et al., 1989. Recommendations for quantitation of the left ventricle by two-dimensional echocardiography. American Society of Echocardiography Committee on Standards, Subcommittee on Quantitation of Two-Dimensional Echocardiograms. J. Am. Soc. Echocardiogr. 2 (5), 358-366.

Schmunis, G.A., Yadon, Z.E., 2010. Chagas' disease: a Latin American health problem becoming a world health problem. Acta Trop. 115, 14-21.

Sonnenblick, E.H., 1988. Congestive heart failure and intact sistolic left ventricular performance. Rev. Heart Fail. 4, 164-174.

Sosa Estani, S., Segura, E.L., Ruiz, A.M., Velazquez, E., Porcel, B.M., Yampotis, C., 1998. Efficacy of chemotherapy with benznidazole in children in the indeterminate phase of Chagas' disease. Am. J. Trop. Med. Hyg. 59 (4), 526-529.

Stauffer, J.C., Gaasch, W.H., 1990. Recognition and treatment of left ventricular diastolic dysfunction. Prog. Cardiovasc. Dis.e 32 (5), 319-332.

Viotti, R., Vigliano, C., Lococo, B., Bertocchi, G., Petti, M., Alvarez, M.G., Postan, M. Armenti, A., 2006. Long-term cardiac outcomes of treating chronic Chagas disease with benznidazole versus no treatment: a nonrandomized trial. Ann. Intern. Med. 144 (10), 724-734. 